REVIEW

\title{
Emergency physicians in critical care: a consultant's experience
}

\section{T Brown}

Emerg Med J 2004;21:145-148. doi: 10.1136/emj.2003.012401

There is a growing interest in the interface between emergency medicine and critical care medicine. Previous articles in this journal have looked at the opportunities and advantages of training in critical care medicine for emergency medicine trainees. In the UK there are a small number of emergency physicians who also have a commitment to critical care medicine. This article describes a personal experience of such a job, looking at the advantages and disadvantages. Depending upon future developments in the role of emergency medicine in the UK, together with the proposed expansion in critical care medicine, such posts may become more common.

Correspondence to: Mr T Brown, Accident and Emergency Department, Whiston Hospital,

Warrington Road, Prescot, Merseyside L35 5DR, UK; terry_b35@hotmail.com
$\mathrm{T}$ his article is one of a series looking at the interface between emergency medicine and critical care medicine. Previous articles have dealt with the training requirements for dual training in emergency medicine and critical care medicine. ${ }^{12}$ I have been a consultant in emergency medicine/critical care medicine for the past five years, and in this article I hope to outline the advantages and disadvantages of such a post, together with some speculation as to what the future holds.

In line with current trends, the term critical care medicine is used rather than intensive care, and emergency medicine rather than accident and emergency medicine.

The views expressed are my own, although I have incorporated comments and viewpoints from the other emergency physicians/critical care consultants in the UK.

\section{BACKGROUND}

Currently, in this country, only $7 \%$ of consultants in critical care medicine are non-anaesthetists. At the time of writing this article, there are less than 10 consultants in emergency medicine/ critical care medicine, but more such posts are being created (four in the Northwest Region in the next six months). Indeed, there is sufficient interest among trainees in emergency medicine that the Northwest Region has designed an emergency medicine specialist registrar (SPR) training programme, which will allow for intermediate level accreditation in critical care medicine.

So, how did this come about?

Since the creation of casualty surgeons in the early sixties, the growth of the specialty of emergency medicine has seen a shift in emphasis from the minor to the major, and from orthopaedics to acute medicine/critical care medicine. Emergency physicians in this country are extending their scope of practice to encompass therapies that have traditionally been the province of acute general physicians, anaesthetists, and critical care doctors.

The increasing subspecialisation of physicians at SPR level, together with the reduction of junior doctors' hours, has led to the concern that physicians in training do not receive appropriate exposure to acutely ill adults. ${ }^{3}$ Indeed, there is a growing perception that we may be seeing the demise of the acute general physician. As a result, some trainees who are interested in acute general medicine are choosing to seek SPR posts in emergency medicine, as they (rightly) perceive that there is no specific training programme in acute general medicine.

Alongside the influx into the specialty of trainees interested in acute medicine, the specialty itself has pursued the Australian/North American model of emergency medicine, in increasing the skills and scope of practice in terms of the treatment of the seriously ill and injured.

The de-skilling of general physicians in the management of critically ill adults means that the responsibility for the assessment and initial treatment of these patients while in the emergency department has fallen to the emergency physician.

Similarly, the severe pressure on critical care beds has led to critically ill patients being treated with advanced therapies for several hours in the emergency department while a bed is found for them. ${ }^{4-6}$

The need for a consultant emergency physician out of hours in the department has many similarities with the need for a critical care consultant out of hours (box).

Critically ill patients need critical care on arrival in the emergency department. It has been shown that the care of patients before admission to the critical care unit is often suboptimal. ${ }^{7}$ It is important that these patients receive high quality care in their time in the department as this has been shown to improve their subsequent mortality and morbidity. ${ }^{8}$ Although there is no evidence that consultant based assessment for these patients immediately upon arrival improves care, there is a certain face validity in the seamless transition from arrival in the emergency department through to admission to the critical care unit.

\section{JOB PLAN}

The job plans of the current emergency physician/critical care consultants are similar across 
The need for a consultant emergency physician out of hours in the department

- Critically ill or injured adults

- Critically ill or injured children

- Organisational issues

- Telephone advice

- (SHO no shows)

- (Waiting times)

Items shown in parentheses are not universally accepted as valid reasons for an emergency consultant presence out of hours.

their various trusts. The main commitment is to the emergency department, with a sessional commitment to critical care, usually for a 24 hour period at a time including on call, at least once per week (table 1).

The administration/teaching commitment is mainly to the emergency department, although this reflects personal choice rather than organisational influence.

Where the job plans differ is in the areas of dual cover and cross cover. Some consultants are on call for both the emergency department and the critical care unit when on call. This has the advantage of avoiding duplication in terms of care of the critically ill or injured adult attending the department. It is very intense, however, and doubts have been raised as to how sustainable this arrangement is with the increasing intensity of out of hours cover for both specialties.

In some trusts there is complete cross cover, in that critical care consultants (who have received no formal training in emergency medicine) cover the emergency department out of hours. This has the advantage of requiring less frequent on call for the emergency physicians, but again there may be problems with credibility, efficacy, and sustainability.

One proposed solution is a modular job plan, with a consultant being dedicated to either the emergency department or the critical care unit for several months, then rotating to the other department for several months and so on. This is the plan for the future in my trust and in neighbouring trusts that are creating similar dual posts.

I work in an 800 bedded district general hospital, which has a 14 bedded critical care unit, comprising an eight bedded intensive care unit and a six bedded high dependency unit. The hospital houses the regional burns and plastics unit, and critically ill burns patients are cared for in the general intensive care. There are six critical care consultants and four emergency physician consultants. The critical care consultants comprise three anaesthetists, one professor, and two emergency physicians. The imposition of the European Working Time Directive has led to the creation of a further post in emergency medicine and a further post for another critical care physician. It is probable that the next appointment of a consultant in critical care medicine will be another emergency medicine consultant.

\section{BENEFITS}

The benefits of such an arrangement can be considered from the point of view of the patient, the department, and the doctor.

\section{The patient}

The fact that critically ill patients are treated on arrival by the consultant on call for both the emergency department and the critical care unit leads to seamless care for that patient as they progress through the department and into the critical care unit.

The start of early, goal directed treatment for critically ill patients has been shown to improve outcome. ${ }^{8}$

\section{The department}

The presence of an emergency physician/critical care consultant in the emergency department inevitably leads to a "washover" of critical care skills into the department. As a result, both doctors and nurses in the department gain exposure to skills and treatments that normally take place in the critical care unit. This causes a great increase in job satisfaction and a rise in quality of these staff.

The knowledge that an emergency department has strong links with critical care, and encourages interventional practice in its trainees makes such a department a very attractive choice for enthusiastic, high quality trainees (in particular those who wish to specialise in emergency medicine). Thus, recruitment and retention of trainees becomes easier, and the standard of doctor applying increases.

In my trust we have developed a critical care rotation at senior house officer (SHO) level, which entails daytime commitment to emergency medicine, acute general medicine, anaesthesia, and critical care. Out of hours the on call commitment is purely to critical care, reporting directly to the consultant on call. Although designed for trainees interested in any of the above careers, we have found that $90 \%$ of trainees who take this post do so as part of training towards an SPR post in emergency medicine. This rotation permits unparalleled experience in managing critically ill patients, and provides superb training for those trainees before starting a post as an SPR in emergency medicine. It also provides a base for further training in critical care medicine for those trainees who wish to attain intermediate level recognition.

Similarly we provide the facility for SPRs in emergency medicine to spend time on secondment in the department, or more formally in a full time middle grade training post, to gain dual accreditation in emergency medicine and critical care medicine.

Finally, the presence of emergency physicians on the critical care unit raises the profile of the emergency department in the trust. The demonstration that emergency physicians are capable of managing patients on the critical care unit is a useful reminder to less enlightened colleagues

\begin{tabular}{|c|c|c|c|c|c|c|}
\hline & $M$ & $\mathrm{~T}$ & w & $\mathbf{T}$ & $\mathbf{F}$ & $S / S$ \\
\hline $\mathrm{AM}$ & $\begin{array}{l}\text { Notional half } \\
\text { day }\end{array}$ & $\begin{array}{l}\text { Critical care } \\
\text { unit }\end{array}$ & $\begin{array}{l}\text { Observation } \\
\text { ward }\end{array}$ & Review clinic & $\begin{array}{l}\text { Critical care unit } \\
\text { weekly audit }\end{array}$ & On call $1: 6$ \\
\hline PM & $\begin{array}{l}\text { Emergency } \\
\text { department } \\
\text { shop floor }\end{array}$ & $\begin{array}{l}\text { Critical care } \\
\text { unit and on } \\
\text { call }\end{array}$ & SHO teaching & $\begin{array}{l}\text { Emergency } \\
\text { department shop } \\
\text { floor/admin }\end{array}$ & $\begin{array}{l}\text { Emergency } \\
\text { department shop } \\
\text { floor/admin }\end{array}$ & (split weekend 1:3) \\
\hline
\end{tabular}


in other specialties that the emergency physician has expertise in the management of critically ill patients, as well as being able to treat the "walking wounded".

\section{The doctor}

Providing a commitment to critical care ensures that my clinical skills and knowledge are kept fresh and up to date. All of the consultants currently working as emergency medicine/critical care doctors report that this is the major reason for taking up such a post. In addition, they report greater job satisfaction.

Being in charge of both the emergency department and the critical care unit when on call allows for the flexible use of beds on the critical care unit for acutely ill patients in the emergency department, with no possible conflict of interest. Not spending hours in the emergency department pleading a patient's case to colleagues in a full critical care unit produces a significant improvement in stress levels!

\section{DISADVANTAGES}

Similarly, the disadvantages of the post can be considered from the point of view of the patient, the department, and the individual.

\section{The patient}

Although I believe that there are no disadvantages for critically ill patients with this arrangement, other patients may suffer. Occasionally, there is a demand for the consultant on call to be present in both the emergency department and the critical care unit. If the need for the consultant in the emergency department is for sheer volume of low acuity patients, there is a tendency for the patients in the critical care unit to take precedence. The view that dealing with large volumes of non-urgent patients in the emergency department is an appropriate use of an emergency physician's time is by no means universally held by consultants in the specialty, however the patients waiting in the department would probably disagree.

\section{The department}

Because of the tendency of patients in the critical care unit to have first call on the consultant's time, the overworked and overstressed staff in the emergency department may feel unsupported in these circumstances, with the resultant effect on morale.

It is inevitable that if you have a commitment to critical care, then time spent on the critical care unit is time taken from the emergency department commitment. If three sessions per week are spent on critical care, and there is no reduction in time spent on administration and teaching, then the amount of time left for "shop floor" commitment to the emergency department is greatly reduced. In addition, whenever doctors are committed to separate areas (split sites, National Health Service and university, separate specialties), there is the danger that staff in each area may perceive themselves to be the "poor relation". This is especially true for staff in the emergency department who often (rightly) perceive themselves to be undervalued, whereas critical care units may be thought of as glamorous and valued by patients and staff alike.

Many emergency departments are increasing their out of hours shop floor cover at consultant level. If an individual consultant is already present in the hospital out of hours at least once per week (as is almost inevitable when on call for the critical care unit), it may be difficult to sustain additional unsociable hours spent in the emergency department.

The implementation of the European Working Time Directive means that compensatory rest periods need to be provided after a disturbed night on call. As the last is the norm for critical care consultants in this (and probably most) trusts, this will further reduce the daytime presence of consultants in the emergency department.

Finally, as the specialty of emergency medicine continues to develop, the credibility, efficacy, and capability of a nonemergency physician providing consultant cover for the emergency department out of hours may be questioned.

\section{The doctor}

Being on call for two specialties at the same time can be very onerous. Even if the consultant is only on for one specialty at a time, there are still problems with dual posts such as these.

I spend less time in the emergency department than my colleagues who are purely emergency physicians. This can cause staff in the department to perceive the latter to be more committed to the department. It requires extra effort to earn loyalty and develop ownership of the emergency department in such circumstances.

As is often the case with dual roles, the staff in the emergency department can perceive you as a critical care consultant who occasionally pops in to the emergency department, while the critical care staff perceive you as an emergency physician who occasionally pops in to the critical care unit. It can be difficult on occasion to remember who you "belong" to.

The dual nature of the post also requires a commitment to continuing professional development for both specialties, which increases the requirement for professional and study leave.

\section{THE FUTURE}

I believe that there are three possible directions that the emergency physicians may take in relation to the emergency medicine/critical care interface:

- The growing interest among emergency medicine trainees in the emergency medicine/critical care interface may lead to an increase in the number of emergency physicians who also have a commitment to critical care. The obvious benefits to the patient, the department, and the reduced frequency of on call for critical care colleagues, may lead to an increasing number of trusts wanting to employ such consultants. The proposed national expansion of critical care beds ${ }^{9}$ will mean an increasing requirement for suitable numbers of appropriately trained consultants. The proposals of the Faculty of Accident and Emergency Medicine for manpower planning suggests a move towards multi-consultant departments, ${ }^{10}$ and in such departments the opportunity to develop subspecialty interests may be available.

- The expansion of the role of the emergency physician in the initial management of the critically ill and injured, together with proposals that emergency physicians provide advanced airway management in the department, ${ }^{11}{ }^{12}$ may mean that emergency physicians gain the exposure to critically ill patients that led myself and other emergency physicians to work in critical care. Given the disadvantages of the dual role mentioned earlier, it may be a more attractive option to be a pure emergency physician, providing advanced care in the emergency department that previously would have been supplied by anaesthetists or critical care physicians. Such a model has been adopted in parts of North America and Australia

- The potential demise of the acute general physician may result in emergency physicians taking on aspects of that role. Thus, the emergency physician may take on responsibility for the first 24 hours of care of all patients presenting to the department (as happens in parts of Australia). Some trusts in this country are already considering the use of emergency physicians in the 
running of their medical assessment units, and clinical decision units are being piloted in several sites in the UK. If the specialty takes on this role, the associated expansion in workload may preclude the opportunity to also have commitment to the critical care unit.

Thus, the number of emergency physicians who also have commitment to critical care may increase or decrease over the next decade, depending upon which model proves the more popular.

For those trusts or people who are interested in such a post, the requirements are: motivation of all concerned, flexibility of colleagues, and good working relationships with consultant colleagues in the emergency department and the critical care unit.

The last requirement is crucial, as the holder of such a post must feel comfortable about seeking help from colleagues if particular expertise is needed (this applies both to emergency physicians covering critical care and critical care physicians covering the emergency department.

\section{ACKNOWLEDGEMENTS}

The author would like to thank the following for their comments and opinions: Dr C O'Donnell, consultant in emergency and critical care medicine, Whipps Cross Hospital, Leytonstone, London; Mr Patrick A Nee, consultant in emergency medicine and critical care medicine,
Whiston Hospital, Prescot, Merseyside; Dr William Tullett, consultant in emergency medicine and critical care medicine, Western General Hospital, Glasgow; Dr Tim Parke, consultant in emergency medicine and critical care medicine, Southern General Hospital, Glasgow.

\section{REFERENCES}

1 Shelly MP. A\&E/ICU interface: training in intensive care medicine. Emerg Med J 2001;18:330-2.

2 Cooper A. Training in intensive care medicine: an accident and emergency trainee's perspective. Emerg Med J 2002;19:106-8.

3 Black CM. Acute medicine: the physician's future role. J R Coll Physicians Lond 2000;34:235-8.

4 Varon J, Fromm RE, Levine RL. Emergency department procedures and length of stay for critically ill medical patients. Ann Emerg Med 1994;23:546-9.

5 Fromm RE, Gibbs LR, McCallum, et al. Critical care in the emergency department: a time based study. Crit Care Med 1993;21:970-5.

6 Graff LG, Clark S, Radford MJ. Critical care by emergency physicians in American and English hospitals. Arch Emerg Med 1993;10:145-54.

7 McQullan P, Pilkington S, Allan, et al. Confidential inquiry into quality of care before admission to intensive care. BMJ 1998;316:1853-8.

8 Rivers E, Nguyen B, Haustad S, et al. Early goal-directed therapy in the treatment of severe sepsis and septic shock. N Engl J Med 2001;345: 1368-77.

9 Department of Health. Comprehensive critical care-a review of adult critical care. London: Department of Health, 2000.

10 Faculty of Accident and Emergency Medicine. Workforce planning in A\&E Medicine 2001-2010. (http://www.faem.org.uk).

11 Mesa Z, Redhead J. Airway management defines the speciality of emergency medicine. J Accid Emerg Med 2000;18(suppl).

12 Clancy N, Nolan J. Airway management in the emergency department. Emerg Med J 2002;19:2-3. 